\title{
The participation of the municipalities in the creation of urban agglomerations
}

\author{
Dmitri Loginov ${ }^{1, *}$, and Elena Karanina ${ }^{1}$ \\ ${ }^{1}$ Vyatka State University, Moskovskaya str., 36, Kirov, 610000, Russia
}

\begin{abstract}
Urban agglomeration is an effective way of providing additional impetus to the development of major cities and surrounding areas. Realization of this advantage is hampered by the fragmentation of municipalities, resulting in the formation of urban agglomerations around the administrative centers of constituent entities of the Russian Federation. The authors of this study propose to consider the possibility of integration of municipal entities forming in the future agglomeration, inter-municipal Association, with a subsequent transition to the formation of a unified municipal formation. Such a decision is justified by the example of the agglomeration of the regional center of the Kirov region - Kirov and surrounding areas.
\end{abstract}

\section{Introduction}

Today, many people are interested in how the rest of the spatial development of the regions in the future. The authors of the present article is concerned with the processes of stratification and separation in many areas. Such processes can lead to delays in the development of individual regions.

The territory, characterized by slow development, over time, may lose economic and political independence, leading to the possibility of their connection to other, economically more successful regions. In such cases, the country could lose a unique set of regions, creating its unique image. Together with the reduced set regions may be a reduction of the development potential of the national economy, as together with the disappearance of the region to the area it occupies will decrease business activity, and will begin the process of out-migration, which means the weakening of the human potential of the territory.

The aim of our study is to reveal the role of municipalities in the formation of large urban agglomerations in the administrative centers of Russian regions.

The hypothesis of the study is that the modern activities of Russian municipalities in the regional centres must be adapted to the new challenges of regional development - the formation of large urban agglomerations. Modern development of Russian urban agglomerations are investigated in the works of V. Belousov, V. Glazyev, E. Goryachenko, Lola A., T. Laurel, M. Mikhailova, E. Safonova, and other professionals.

\section{Materials and Methods}

\footnotetext{
* Corresponding author: doctorloginov@mail.ru
} 
For the Russian Federation the question of the formation of urban agglomerations is of particular importance. This is due to the fact that Russia has a significant concentration of business activity in the major cities: the capital city of Moscow and the second largest and important city in the country - St. Petersburg. Of course, in Russia known other beautiful cities, the population of which exceeds one million people. The cities are important for industrial and cultural development of Russian society, but they are not quite cope with the role of alternatives to the two leading cities of Russia. This is evident in migratory streams that are still closed to Moscow and St. Petersburg. The authors are convinced that to ensure balanced development of Russia, especially its economic development, it is necessary to form a network of large cities, providing opportunities for implementation of investment projects and fulfillment of people, not smaller, than in Moscow and St. Petersburg. At the same time we should not forget that such alternative cities should not be limited to cities with populations exceeding one million people. The fact that each region must be the prospect, including in such regions, the administrative center of which is a relatively small city.

Indeed, Russia's regions are very diverse. The administrative centers of many of them are old Russian towns, whose numbers are relatively small. This indicator can be calculated at the level of several hundred thousand people. From some point of view, such a city can be considered unpromising for economic development. He may not be the most advanced positions on the development of science and education, it may be critically a small number of large industrial enterprises, its human resources may not be optimal in structure, for example, by educational level or by age. It is well known that the economy of the region largely depends on the economy of its administrative center. Thus, the lack of prospects of the administrative center of the region dramatically reduces the ability of the economy of the region as a whole. This situation is dangerous because the region, showing not the best indicators of economic development, has generally weaker compared to other regions, the tax potential, his budget is not enough income. All of this can lead to the decision to join a region to another, larger.

Imagine that the described process has taken place. For the country as a whole, it can be quite positive, as the potential for a stronger region will be used to provide social obligations to the population of the weaker region. However, the authors believe that this win is mostly tactical in nature. In the strategic plan for the first plan can leave negative effects. In particular, the territory lost its status as a regional centre, will be doomed to further degradation, migration, attenuation of the intensity of cultural, scientific, educational and business life. The result is lost a unique set of competencies, unique for this area. In the longer term, the integration of regions can be dangerous appearance of anthropogenic deserts, the existence of which implies under-utilization of the natural potential of the territories.

While agreeing that the implementation of negative socio-economic impact of integration of regions is undesirable for a country, we need to find ways of preventing such a perspective. And should prove economically justified way of constructive overcome of the difficulties today experienced by many regions, namely in the industrial downturn and the deterioration in the demographic situation. The authors are convinced that the solution to the problem of lagging regions in socio-economic development can be found through the adoption of comprehensive measures for the development of urban agglomerations in the administrative centers of the regions. Education agglomeration sufficiently profitable for the region, as the city is the administrative center of the region, has the ability to retain its key benefits such as unique historical and cultural character, cultural, intellectual and competence-building of local society, and at the same time to acquire those characteristics that prevent its further development to strengthen industrial capacity, to increase the population and create new platforms to improve the comfort of the urban environment, 
including areas for investment in new industrial facilities and the creation of modern business infrastructure and the construction of comfortable residential areas.

\section{Results}

In the modern world discussion of the spatial aspects of economic development it is increasingly focused on the discussion of urban development. Indeed, the city, especially big city, amalgamate the business activity of the surrounding space. The city forms the competitiveness of the region, as it is the city's largest regional enterprises. The city also is within human potential, which is the most important resource of modern economic development in the conditions of formation of a postindustrial society. It should be understood that the human potential, in contrast to the natural resources of the region requires special conditions for the formation, maintenance and development. Such conditions include, first of all, comfort of environment, the possibility of obtaining advanced education, internship opportunities, gain practical experience, build a successful career. All of these requires that the city wide infrastructure. It was her lack of and makes part of the population, usually the most active and ambitious, look for opportunities for self-actualization in large cities in Russia often in the capital.

Thus, the main condition for the development of the city, which is the regional center, it infrastructure development support human capabilities. Definitely need more jobs, enabling people to work, earn income and realize their dreams. However, in the context of the concept of postindustrial society need to recognize that human initiative, including entrepreneurship, creativity, labor, social initiative becomes, ultimately, the very factor of job creation, which in the traditional, conventional sense is perceived more as the result of the administrative-political effort. Indeed, perfectly formed human potential of major cities, under structure, the high business activity and have attained a number of the critical mass at which the competition of individuals begins to catalyze the processes of enterprise creation and the implementation of investment projects has the ability to self-reproduce. People who grew up in a comfortable city, it received good education, implement projects that form the structure of the economy of the city and the whole region. This conclusion confirms the necessity of the transformation of the regional centres in urban agglomerations, comfort and the possibility of human self-development approaching the level of the capital.

However, despite the obviousness of the creation of large urban agglomerations in the regional centers of this process is too slow. Among the reasons is lack of investment in infrastructure, and serious institutional restrictions. It is known that the territory of the Russian Federation is divided into a separate municipality, under which local selfgovernment. As a rule, the administrative center of a constituent entity of the Russian Federation forms the territory of the municipal district of the city, touching its borders with the suburban areas formed in other municipalities, among them the city districts and municipal areas. The integration of the regional centre and its satellite towns, often within the same Metropolitan area is often hampered by the unwillingness of the respective municipalities to join.

Formation of urban agglomerations is a form of inter-municipal cooperation [1]. Such cooperation necessitates the solution of such tasks as making decisions about the implementation of investment projects covering several municipalities, joint financing and implementation of inter-municipal coordination, coordination of actions of individual parties. This practice was unusual and unexpected for most municipalities, are presented as urban districts and municipal regions and urban settlements.

Despite the fact that the municipalities are obliged to carry out a significant number of state powers transferred to their level, development of inter-municipal cooperation in the framework of the formation of urban agglomerations includes primarily the implementation 
of the municipal authority. To ensure effective inter-municipal cooperation municipalities in the creation of urban agglomeration, there should be a careful revision of local values, which are vested in the local authorities. Among such powers it is necessary to allocate the execution of state and municipal functions and the provision of public and municipal services.

Function in its most General form is a specialized action, rather narrow work, the implementation of measures to implement certain obligations. In a sense, function is the role, the mission of the subject under consideration. Functions of municipalities should be seen primarily as the process of implementation of powers of local value. Among the major municipal functions can be identified such as the adoption by local government for local solutions, publishing legal acts of local authorities, municipal property management and local Finance, control and supervision in the framework of its powers, and the provision of municipal services. In modern conditions, the transition to a postindustrial society, in the framework of the principles of open government must recognize that to the fore among these municipal functions must be made by the provision of municipal services. This priority emphasizes the service nature of contemporary public administration, focused on the needs of the local population.

Of course, municipal services are not homogeneous, their range is quite wide, which corresponds to the variety of tasks performed by local authorities for the welfare of the population. In this regard, to facilitate understanding of the process of providing municipal services and organize methodological support of this procedure, it is advisable to introduce a certain classification of municipal services. In particular, among the municipal services are reviewed such consolidated group as the administrative and fiscal services. Indeed, the actions of local administrations, which aim at public service in the form of subsidies or disclosure may be referred to administrative services. Not accidental for their implementation, the public authorities issue so-called administrative regulations. At the same time, there are a number of municipal services that require specialized, professional organizations, whose activity is financed from the local budget. These include organizations of health, education, culture and leisure, sport and physical culture, public service and public works. The number and range of such services are determined by the financial possibilities of the local administration, which, in turn, depend on the income of the local budget [2].

In addition to fiscal services, there are also private services provided by organizations of different ownership forms at the expense of the recipient. Local authorities, within their powers contribute to the development of private services in the territory of the municipality.

There is another principle, according to which it is necessary to differentiate the state (municipal) services and the state (municipal) functions. While the public service is characterized as the activity of the Executive authority for the execution of the request of physical or legal persons for the receipt of material and financial resources in cases stipulated by the legislation and about providing them with documented information. "State is characterized as a function of the activity of Executive authority for management decision-making and its implementation within the established deadlines or the transfer of documented information not related to the direct appeal (claim) of the citizen or organization" [3].

In this case, the concept "state (municipal) functions" and "state (municipal) services" exclusively apply to the activities of the Executive authorities, and the concept of the state (municipal) services meet the definition of administrative services. However, for the organization of inter-municipal cooperation in urban areas must consider not only the activities of local governments performing municipal functions and organizational activities, carried out by order of the local authorities and financed from the local budget, that is, the provision of public services. 
Therefore, it is advisable to use the classification methods of implementation of powers of local self-government bodies on issues of local importance, including the implementation of the municipal functions of local authorities and the provision of public services by various organizations.

Forms of organization of inter-municipal cooperation in urban agglomerations on the exercise of municipal functions and provision of public services during the construction phase when the classification will vary. Since the implementation of the municipal functions takes place with the direct participation of local governments, the organization of inter-municipal cooperation is possible through the creation of inter-municipal bodies and transfer of powers of local authorities for the execution of municipal functions. However, the creation of inter-municipal authorities will increase the number of management levels, the increase in the number of administrative staff and expenses on its maintenance. On the part of municipalities may have certain concerns about the partial loss of independence and political weight of the head of the municipality. In addition, the creation of inter-municipal management bodies is not provided for in domestic law. Therefore, the use of this form of inter-municipal cooperation is not necessary.

In such a case it is proposed to limit joint activity in the framework of the Association of municipalities, which will help them in the performance of municipal functions: to provide methodological and Advisory support, to organize the work of coordination councils and working groups to develop model municipal legal acts, to ensure the exchange of experience, etc. in addition, the Association of municipalities falling within urban agglomeration should also be aimed at forming a shared vision of strategic prospects of development of the urban agglomeration; approval of the plans and projects of development of municipal entities; ensuring integrated development of the territory of the urban agglomeration and land use.

Forms of organization of inter-municipal cooperation for the provision of public services can be determined by the nature of public services, which may be inherent in the external effects and (or) the economies of scale. Externalities arise when the fiscal services provided in one municipality have an impact on the quality of life of the inhabitants of other municipalities or if the residents of one municipality can make use of budget services provided to other municipal entities, does not compensate for the costs of their provision. Economies of scale occur if unit costs for the provision of public services decrease with increase in the volume of its provision.

For most public services characterized by external effects. This is due to the fact that the population of one municipality, arriving to the territory of another municipal formation, becomes a potential consumer of budget services in the area. The economies of scale typical of much smaller number of public services associated with the construction and operation of large facilities electricity, heat, gas and water supply; road activities; utilization and recycling of household and industrial waste.

Inter-municipal cooperation for the provision of public services, which are characterized by external effects, it is advisable to implement through the conclusion of contracts on purchase of services by one municipality from another. Inter-municipal cooperation for the provision of public services for which economies of scale should be implemented in the form of intermunicipal economic societies, as well as funds for co-financing the construction.

As you can see, the most appropriate forms of organization of inter-municipal cooperation in urban areas to address issues of local importance, including the forms of organization of inter-municipal cooperation for the execution of municipal functions and forms of organization of inter-municipal cooperation for the provision of public services.

Describes the forms of organization of inter-municipal cooperation in urban areas can be used in the practical activity of municipalities within the urban agglomeration, in order 
to improve the efficiency and effectiveness of solving issues of local importance. Organization of joint activities in the framework of inter-municipal cooperation will contribute to the effective use of resources municipalities will provide the increase of volumes and improvement of quality of services provided to the population of municipalities.

Under the influence of the territorial concentration of production and other economic facilities is the agglomeration effect. It stems from the fact that, as noted in the literature, compact objects, if they are compatible, there are always more effective than the same objects placed in isolation. In fact, the agglomeration effect and makes the urban agglomerations of points of growth in regional development, as evidenced by numerous data on the contribution of the largest urban agglomerations in the economies of the regions where they are located [4].

The main criteria for the allocation of agglomerations today assumed the presence of the city core, with the population over 100 thousand people and not more than 1.5-2-hour transport accessibility to at least two other towns or urban-type settlements, gravitating to the core [5]. The most common monocentric agglomeration with one core, which is subject to their influence of the surrounding municipalities. In this case - surpasses neighboring municipalities as population and economic development [6].

The greatest interest in the problems of formation of urban agglomerations emerged in the second half of the twentieth century and was associated mainly with the 1960-1980-ies. During this period, the planned economy in Russia was formed mainly industrial urban agglomerations on the principle of convenient groups of plants (and create associated value-added chain) and placing them near production centers of necessary manpower [7]. The inclusion of certain settlements within the Metropolitan area was defined primarily by the presence of industrial relations of these settlements with the kernel.

The modern stage of formation of urban agglomerations has features that distinguish it from second half of XX century, when formed industrial agglomerations. Radical changes in Russian society in the last 25 years, requires a new understanding of the processes of agglomeration growth, adequate to modern conditions. Today experts talk about the innovative processes associated with the renewal of the Russian economy [8].

Currently, it is necessary to reconsider the very idea of agromeridian, because today, agglomeration is characterized not so much by the production and integrity of settlement systems as the integrity of the markets: labour, real estate, land, and also a level of functional coherence of its separate elements [9]. Development of agglomerations should be based primarily on the development of horizontal connections. The creation of urban agglomerations should be considered as one of the strategic directions of spatial development of the country, allowing to create the skeleton of the control system [10].

Time, there is two points of view on the problem of formation of urban agglomerations. On the one hand, it is stated about the special relevance of agglomerations in Russia, with its vast spaces and large distances between towns in many regions. This will allow you to structure and accelerate the development of human capital and to create competitive conditions for business" [11]. In addition, through priority development of large urban agglomerations, the macro-region it is possible to successfully concentrate that will significantly increase the manageability and eliminate unnecessary errors in the development. On the other hand, expressed doubts about the possibility of forced the creation of agglomerations in terms of ongoing depopulation of the majority of Russian regions and provides relevant arguments from [12]. The shortage of large agglomerations creates problems for spatial development, the country lacks strong centers, organizing the territory and is able to accelerate the modernization of the periphery [13].

The possibility of creating agglomerations are not just limited to a small number of large centres, but the spatial isolation of many cities, underdevelopment of transport 
communications. According to the authors of this article, one of the most negative aspects of the forced creation of Metropolitan areas due to the shrinking of the population to major cities and thoroughfares for a large part of the country. Under these conditions, sparse settlement system ceases to perform spatial-osvensky and military-political functions, successful implementation of which is necessary for the security of the country. In addition, the process of agglomerating can generate a number of negative social consequences, such as increases in inequality, rising crime and worsening environmental problems [14].

As you can see, still remain uncertainties in the theoretical comprehension of the essence of the agglomeration process and the development of specific methods of diagnostics of the situation and estimated prospects of development of urban agglomerations, which should be based on integrated interdisciplinary research [15]. The methodological basis for analysis of the situation and evaluation of perspectives of development, in our view, should be the idea of city regions as complex socio-economic system, which is formed naturally under certain conditions. From our point of view, agglomeration is impossible to create on the initiative of public authorities, it is not administrative-territorial unit, formed by simple fusion of elements from a primarily managerial interests. And it should be borne in mind that urban agglomeration is not simply a production system or settlement system, and naturally formed a specific socio-territorial object [16]. Therefore, existing approaches to the study of urban agglomeration, and the evaluation of its effectiveness from economic and geographic points of view, from the standpoint of the theories of settlement or management theories should be supplemented by a sociological understanding of the processes.

\section{Discussion}

Given the fact that urban agglomeration is a naturally formed a specific socio-territorial object the regulation of the formation of urban agglomerations is appropriate and effective in those cases when there is a natural socio-economic background [17]. In this regard, there are the problems of diagnostics of prerequisites for the formation of urban agglomerations and barriers for their development. Sources of information in such a socio-diagnostic study should, in our opinion, serve as statistical data, expert evaluation as well as data of sociological surveys of the population. The prerequisites for the formation of urban agglomerations is a conditions and opportunities that promote the development of agglomeration process on site [18]. They are treated as the basic socio-economic potential of the settlements included in the agglomeration, and the degree of differentiation potentials of the settlements. In our opinion, the differences in potentials give rise to intense interaction between the settlements, is actually a sharing of various resources to achieve the agglomeration effect [19]. Diagnostics of the agglomeration of interactions that already naturally exists on-site, their content, intensity, the basic directions will allow to assess the degree of inclusion into a conglomeration areal, delineate its boundaries, to reveal the space structure of the urban agglomeration. At the same time, the on-site circumstances may exist that impede the development of the agglomeration process, barriers to their development. For the diagnosis of these barriers is necessary to evaluate the main problems of the territory, which are factors hindering the agglomeration process [20]. In addition, it is important to consider the unrealized potential of interactions between settlements and possible directions of further development of relations. This is especially true for the assessment of regulatory impact of the agglomeration process.

Speaking about the consequences of the processes of agglomeration growth for individual territories, it should be borne in mind that they can be expressed not only in the sintering effect to be considered primarily from an economic point of view, which, according to the supporters of active formation of urban agglomerations, should be one of 
the factors in the solution of economic problems in the regions [21]. It seems that the consequences of the formation of urban agglomerations is much more diverse, and it is important to consider not only economic but also social effects, and to imagine not only positive, but possible negative effects of the agglomeration process for the territories.

Summing up the study, I want to emphasize that the creation of agglomerations around large cities, especially administrative centres of the regions is almost the only alternative to a gradual loss of competitiveness of regional centres with population less than 500 thousand people. On the example of the Kirov region the authors of the study tried to prove that the process of creating a conurbation around the regional administrative centre opens significant prospects to ensure the new zoning of large urban areas. It is important to emphasize the prospects of creating unique platforms for new business centers, areas of residential development, with architectural uniqueness and industrial sites that meet modern technological, logistical, resource and environmental requirements. According to the authors, over the next 20-25 years in the European part of Russia should receive at least 10 new urban agglomerations with a population of not less than 750 thousand people each.

The material in this article suggests that the modern Russian region can become competitive if built in the centre of the urban agglomeration with an efficient economy and an advanced society. Achieving this goal requires a revision of the role of local governments regional centers in the development of cities. Today it is not enough to manage the regional center as a city. The municipality must take responsibility for the fact that the results of development of the regional centre in znachitelnoy extent determine the competitiveness of the region as a whole.

\section{Conclusions}

Thus, the present study identified a serious trend in the study of the role of local governments in the development of regional centers of constituent entities of the Russian Federation. It is shown that the regional centre of the Russian Federation should assume much of the responsibility for socio-economic development of the region as a whole. This is due to the transition to a postindustrial economy in which the significance of intellectual labor. This is acceptable for a modern, large cities, and even better - of urban agglomerations. In this regard, the authors insist, to recommend to the municipal authorities of Russian regions to Orient the goals of socio-economic development in the gradual formation of urban agglomerations, including in asset cooperation with neighbouring municipalities that form the suburbs of the regional centre. In the future, the present study proposes to develop in the direction of clarify the functions of local governments regional centres to ensure coordination of processes of formation of large urban agglomerations.

\section{References}

1. M.A. Mikhaylova. News of IGEA. 4 (78). 105-109 (2011)

2. L.G. Sokolova. Public management and sustainable development of municipalities: collection of scientific papers. 3. 42-48 (2010)

3. V. Glazychev and I. Starodubrovskaya et al. Chelyabinsk agglomeration: the development potential. (The Institute of Economics and law, Chelyabinsk, 2008)

4. E. Goryatchenko and N.L.Mosienko. Region: Economics and sociology. 3. 94-112 (2011)

5. A.M. Lola, E.P. Menschikova and U.A. Lola. Urban planning. 3 (13). 56-64 (2011)

6. V.N. Belousov. Urban development of Russia in XXI century. 4. 13-17 (2007) 
7. E. Bose. Russian expert review. 4-5 (22). 13-16 (2007)

8. A.M. Lola and A.A. Kolesnikov. Building expert. 13 (272). 2-4 (2008)

9. S. Artobolevsky. Russian expert review. 4 - 5 (22). 9-11 (2007)

10. M. Grudinin and A. Popov. Expert - Sibir. 13 - 14. 11-15 (2011)

11. A.S. Novosyolov. Regional economic policy of the Russian Federation: principles, forms and methods of implementation. 6. 224-254 (2010)

12. R.V. Babun. Problems and prospects of socio-economic development of municipalities of the South of Kuzbass. (Kuzbassvuzizdat, Kemerovo, 2008)

13. Z.Z. Mullagaleeva and V.A. Shabashyov. Theoretical and methodological foundations of economic policy of the cities, forming the Metropolitan area. (Kuzbassvuzizdat, Kemerovo, 2009)

14. A.S. Puzanov and R.A. Popov. City almanac. 4. 147-164 (2008)

15. N.R. Izguzina. European Social Science Journal. 6 - 2 (45). 499-505 (2014)

16. V.N. Papelo, B.A. Kovtun and A.N. Goloshevskaya. Innovations in state and municipal management: the experience of solving social and economic problems. (Federal state budgetary educational institution of higher professional education national research Tomsk state University, Tomsk, 2014)

17. E.E. Goryatchenko and N.L. Mosienko. ECO. 5 (479). 56-68 (2014)

18. V.V. Mischenko and I.V. Mischenko. The contours of global transformations: politics, economics, law. 5 (43). 68-79 (2015)

19. E.A. Safonova. Young scientist. 2 (106). $704-707$ (2016)

20. U.V. Astakhov and A.S. Korolyov. Theory and practice of social development. 3. 17$21(2016)$

21. T.G. Lavrova. Management science in the modern world. 1. 548-552 (2015) 